\title{
ASSESSMENT OF LAKE-SALT FOR SOURCING DIETARY MINERALS.
}

\author{
E.J. Ekanem* and G.F.S. Harrison \\ Department of Chemistry, Ahmadu Ecilo Úniversity. Zaria, Nigeria.
}

\begin{abstract}
An analysis of 43 'kanwa' samples collected from various locations in northern Nigeria. Niger. Chad and Cameroun republics for elements and compounds is reported. Sodium occurred in major concentrations $\left(1-44.5^{\circ}\right.$ ) in all samples; potassium also occurred in all samples but at low levels $\left(0.1-4.7^{\circ}\right)$ except in two samples where it was major $\left(19.6^{\circ} \%\right.$ and $36.5^{\circ} \%$ : zine $\left(0.00028-0.00042^{\circ} \%\right)$, magnesium $\left(0.02-0.06^{\circ}\right.$ ) and aimminium oceurred very rarely: iron $(0.008-0.04 \%)$ was common while chromium oceurred only occasionally. Pink coloured samples always contained manganese $\left(0.0016-0.0055^{\circ} 0\right)$. The major compounds isolated from samples were sodium carbonate, sodium hydrogen carbonate, sodium sulphate and sodium chloride. The quantities of 'kanwa' that may be incorporated into food and feedstuffs to source the minerals for various livestock are suggested in line with the experimentally determined composition. Though "kanwa' may be used to source sodium. potassium. iron and manganese in human food and animal rations, it is unsuitable for magnesium and zine that require excessively large quantities.
\end{abstract}

\section{INTRODUCTION}

'Kanwa' is the Hausa name for natron. a dricd lake salt and a product of the salt industry in many parts of northern Africa. It is importunt as a commodity of trade across the shara desert with a market extending into most of west and central Alrica', It has culinary importance in Africa as a food tenderiser in cooking and as an ingredient in the prepaxation of certain foods ${ }^{1.23}$. Medicinal potency Was been claimed in various localities and it is an ingredient of traditional medicines for ailments like stomach ache, toothache and constipation ${ }^{4}$. It is also applied as an ingredient in snuff and certain local beverages and as a mordant in dycing. 'Kanwa' is administered to animals either in drinking water or in their feed in the belief that it provides essential minerals. It is known to induce diarrhoea when raken in water and has been so applied as a purgative in man and livestock. In the HatsaFulani region of porthern Nigeria, nursing mothers consume large quantities of 'kanwa daily in a pap of guinea corn as part of the forty-day post-partum practice in the belief that it increases the quantity and improves the

*Author for correspondence quality of breast milks. This practice has been implicated in the incidence of the syndrome of peripartum cardiac failure (PPCF) among nursing mothers in this area".

Literalure repons on the chemical composition of hanwa were based on few samples collected from single locations ${ }^{7} \times$. 2 . The wide varicty of 'kanwa' in the market suggests the need to examine a larger number of samples collected over a wide area of distribution of the substance. For this study, samples were collected at various locations selected to reflect the different trade routes by which the commodity arrives in Nigerian markets. The objectives were to determine the chemical composition of 'kanwa' and to examine the speculation that 'kanwa' may be a source of minerals for man and livestock in the light of the chemical composition determined.

\section{EXPFRIMENTAL}

\section{Samples and reagents}

Forty three samples of 'kanwa' comprising 4 from Chad, 4 from Cameroun, 20 from Niger and 15 from Nigeria were analysed for chemical composition using analytical reagent grade 
chemicals and distilled water. Numbers were assigned to identify samples for this study only.

\section{Instruments}

The flame photometer was a GallenKamp Mark 11, F500 and the atomic absorption spectrophotometer was a Perkin Elmer model 306 using the air-acetylene flame.

\section{Qualitative analysis}

Each sample was observed with a hand lens for crystallinity before grinding and storing in a glass bottle. Flame test ${ }^{9}$ and standard methods of qualitative analysis, 12 were applied to detect amions and metallic elements.

\section{Quantitative analysis}

All of each sample was coned and quartered to obtain a sample for quantitative analysis. $1.0 \mathrm{~g}$ of the dry sample was dissolved in water or aqueous hydrochloric acid to obtain a clear solution; certain samples had to be boiled in hydrogen flouride to obtain a clear solution. The solution was made up to 1 litre with water introducing $0.004 \mathrm{M}$ lithium chloride to suppress the ionisation interference observed in the determination of $\mathrm{Na}$ and $\mathrm{K}$ and $0: 04 \mathrm{M} \mathrm{HCl}$ to optimise signal enhancements in the determination of $\mathrm{Fe}, \mathrm{Mg}$ and $\mathrm{Zn}$. Sample solutions were analysed for $\mathrm{Na}$ and $\mathrm{K}$ by flame photometry and for $\mathrm{Fe}, \mathrm{Mg}, \mathrm{Mn}$ and $\mathrm{Zn}$ by flame atomic absorption spectrophotometry.

\section{Bicarbonate/carbonate ratio}

The combined carbonate and bicarbonate content of samples was determined by titrating the samples $(0.5 \mathrm{~g})$ against standard $(0.1 \mathrm{M})$ hydrochloric acid using methyl orange as indicator. The ratio of bicarbonate to carbonate was then determined by titrating the samples with the hydrochloric acid using phenolphthalein and methyl orange successively as indicators. The results were checked against those obtained by pH titrations for a few samples.

\section{Dietary supplementation}

The masses of constituent mineral elements derivable from $\mathbf{l k g}$ of 'kanwa' were used with literature required daily intake of the minerals ${ }^{13}$ to determine the daily consumption of 'kanwa' required by humans to source the minerals. A similar approach was adopted to determine the daily 'kanwa' requirement for various animal rations ${ }^{14-16}$

\section{RESULTS}

\section{Qualitative analysis}

All samples except one were crystalline in texture. Sample colours varied between and within samples. Many samples were light coloured, ranging from white, through orange to transparent while others were dark in colour including grey, brown and black. Most of the light coloured samples were soluble in pure water while others required dilute acid $(\mathrm{HCl})$; most of the dark coloured samples required digestion with hydrogen fluoride to give a clear solution.

$\mathrm{CO}_{3}{ }^{2-}$ was detected in all samples except one and occurred together with $\mathrm{HCO}_{3}^{-}$in all cases. Certain samples also contained $\mathrm{SO}_{4}{ }^{2-}$ and/or $\mathrm{Cl}^{-}$and $\mathrm{PO}_{4}{ }^{3-}$ was detected in one sample. Na and $\mathrm{K}$ occurred in all samples; $\mathrm{Fe}$ occurred in many samples while $\mathrm{Mg}, \mathrm{Mn}, \mathrm{Zn}$, $\mathrm{Cr}$ and $\mathrm{Al}$ occurred in few samples. The results of qualitative analysis are presented with other data in Table 1.

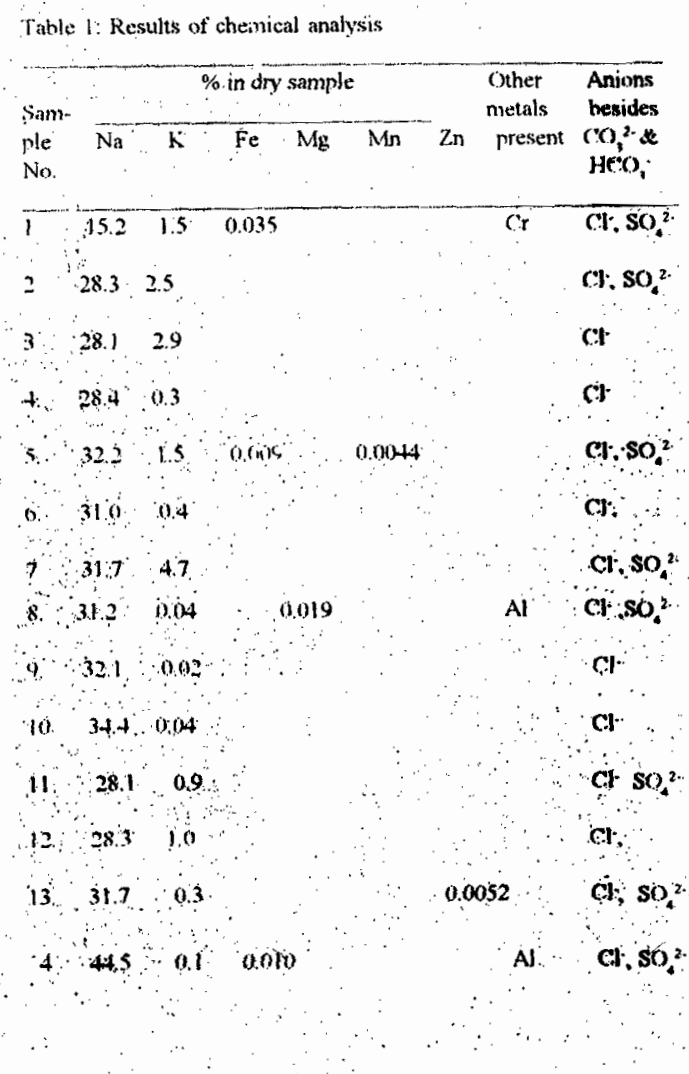




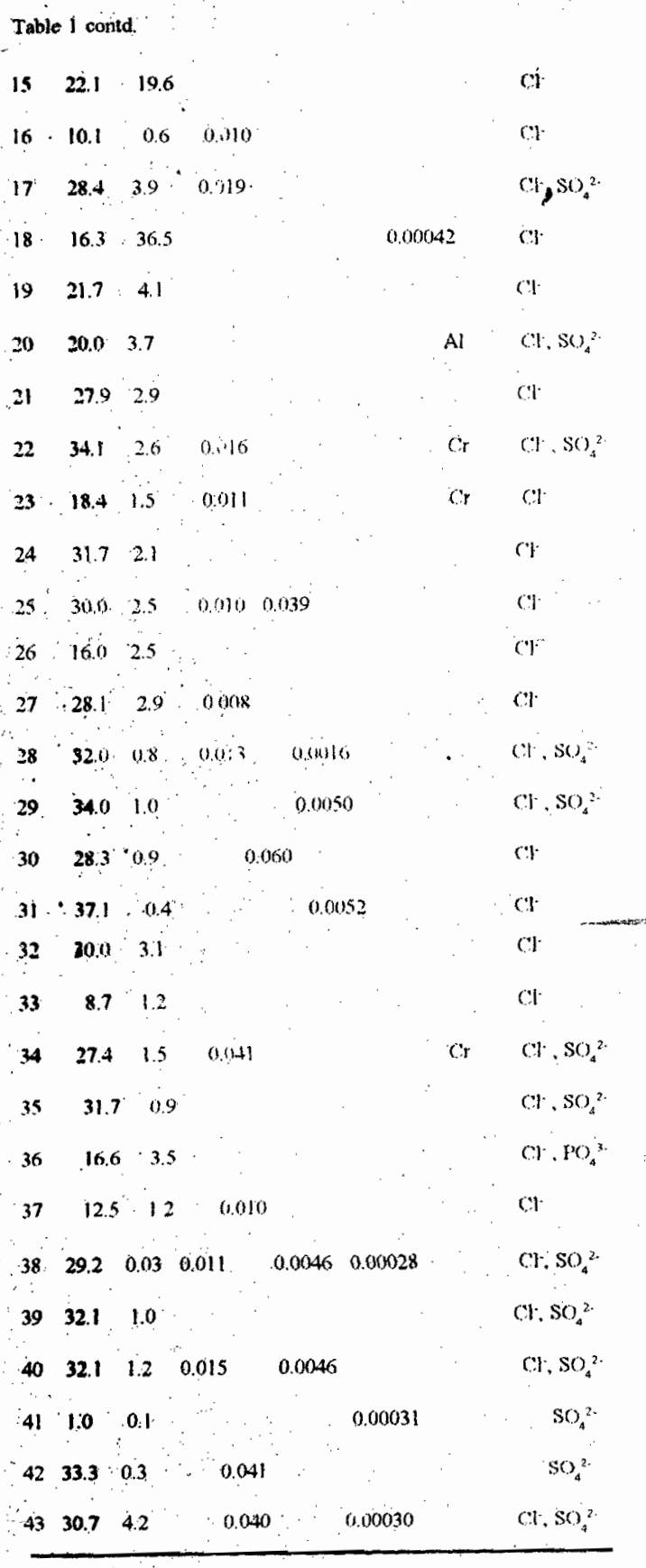

Note: Blank spaces imply metal levels below detection.

\section{(batedatitative analysis}

to

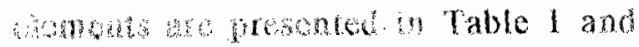
Hombertsed a Table 2 . The burbonate 10

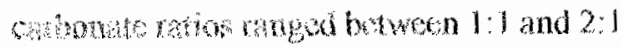

Table 2: Summary of metal concentrutions in samples.

\begin{tabular}{cccc}
\hline $\begin{array}{c}\text { Element Concentration } \\
\text { range }(\%)\end{array}$ & $\begin{array}{c}\text { Mode } \\
(\%)\end{array}$ & $\begin{array}{c}\text { Oecurrence } \\
(\% \text { samples })\end{array}$ \\
\hline $\mathrm{Na}$ & $1-44.5$ & 30 & 100 \\
$\mathrm{~K}$ & $0.1-36.5$ & 3 & 100 \\
$\mathrm{Fe}$ & $0.008-0.041$ & 0.01 & 32.5 \\
$\mathrm{Mg} \quad 0.019-0.060$ & 0.040 & 11.6 \\
$\mathrm{Mn} \quad 0.0016-0.0055$ & 0.005 & 16.2 \\
$\mathrm{Zn} \quad 0.00028-0.00042$ & 0.0003 & 9.3 \\
$\mathrm{Al}$ & - & - & 2.3 \\
$\mathrm{Cr}$ & - & & 9.3 \\
\hline
\end{tabular}

Dietary supplementation

The required daily intake of 'kanwa' that would source minerals in the diet of humans and livestock is presented in Tables 3 and 4 respectively.

Table 3: Required daily consumption of 'kanwa' for humans

\begin{tabular}{lccc}
\hline Element Mass per kg & $\begin{array}{c}\text { AJJI } \\
\text { of 'kanwa' }(\mathrm{g})\end{array}$ & $\begin{array}{c}\text { Daily required } \\
\text { kanwa' }\end{array}$ \\
\hline $\mathrm{Na}$ & 300 & $2.2(0.44)$ & $0.007(0.0015)$ \\
$\mathrm{K}$ & 30 & 4.0 & 0.133 \\
$\mathrm{Fe}$ & 0.1 & 0.010 & 0.100 \\
$\mathrm{Mg}$ & 0.4 & 0.350 & 0.875 \\
$\mathrm{Mn}$ & 0.05 & 0.005 & 0.100 \\
$\mathrm{Zn}$ & 0.003 & 0.015 & 5.000
\end{tabular}

\section{DISCUSSION}

'Kanwa' is common in arid and semi-arid regions and has been described as natron or trona ${ }^{4,6}$ and presented chemically as a mixture

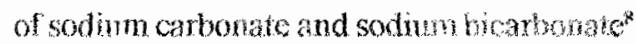

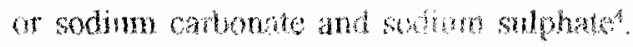

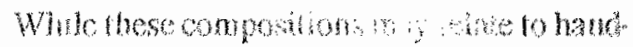

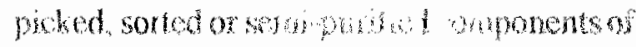

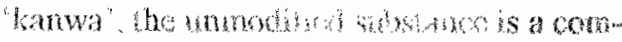

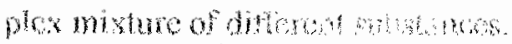


CANDISC was further used to analyse the output data from FASTCLUS. CANDISC performs cannonical discriminant analysis and does both univariate and multivariate one-way analysis of variance. From these, cannonical coefficients were calculated. An important provision of CANDISC is the PLOT algorithm which pairs the cannonical variables ${ }^{12}$ using 'K-means' clustering. Univariate test statistics from the cannonical discriminant analyses were used in correlations.

Results of tests performed with some plant extracts on dogs and rabbits induced with particular ailment are shown in Table $4^{10,11}$. Extracts of the plants FSB, FPB and ASB, al members of cluster 3 , were used and positive results were obtained ${ }^{0,11}$.

\section{RESULTS AND DISCUSSION}

\section{Statistical analysis by elemental contents}

Three clusters (groups) are discernible from the dendrogram. These are, CL9-(XAR, FPR, FTR*); CL10-(MML, HCB) and FTR* and FSB, CL6-(XQR, CPL, CPR, FSB, FSR, FPB) and CL-7 (MMR, ASB) denoted as clusters 1,2 and 3 respectively. These have been classified according to the highest normalized RMS values. It is to be noted that the closer the variables cluster to the left of the dendrogram, the more similar they are; the further apart to the right the more dissimilar. Members of cluster 3 had the highest $\mathrm{Ca}$ and $\mathrm{Mg}$ concentrations with respective ranges of 21.0 $-32.5 \%$ and $0.48-7.3 \%$ (Table 1 ). Cluster 1 members had the highest $\mathrm{K}$ levels $(12.0$ $18.0 \%$ ) while Cluster 2 registered the lowest values of $\mathrm{Ca}, \mathrm{K}$ and $\mathrm{Fe}$ according to this clustering procedure. The observed clustering is further highlighted by Fig. 2 which illustrated

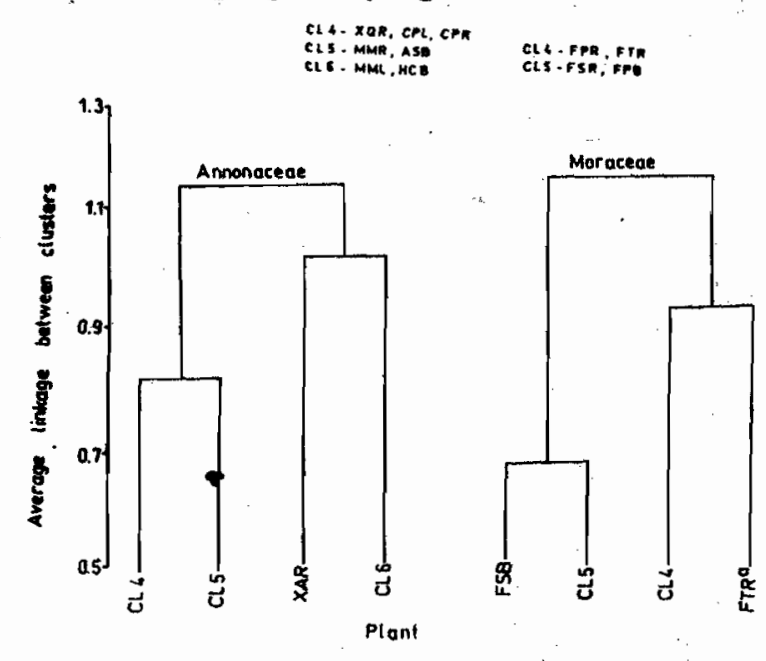

Figure. 2: Averag likage chuster analysis by individual plont tamilies the tree diagram of the individual families. Agreement between Figs. 1 and 2 tends to negate the existence of outliers in the data set.

From table 2 it is noted that respective average values of $\mathrm{K}$. Fe and $\mathrm{Ca}$ are highest for Cluster 1.2 and 3 in that order. The clustering indices for these 3 clusters are within the range of $13.04 \pm 4.35,1.06 \pm 1.26$ and 28.80 \pm 3.36 . The RMS standard deviation between observations within the clusters 1,2 and 3 are $1.73,1.43$ and 1.88 respectively. These help to reflect the nearness of cluster 1 to both 2 and 3 . It is implied that some characteristics of the plant members of cluster 1 are found in members of both clusters 2 and 3 . The absence of a cluster with only one member here once again negates the presence of an outlier within the data set. This is so because FASTCLUS is very sensitive to outliers and constitutes a useful procedure for outlier detection ${ }^{12}$.

CANDISC aids visual interpretation of the group differences. Fig. 3 illustrates the

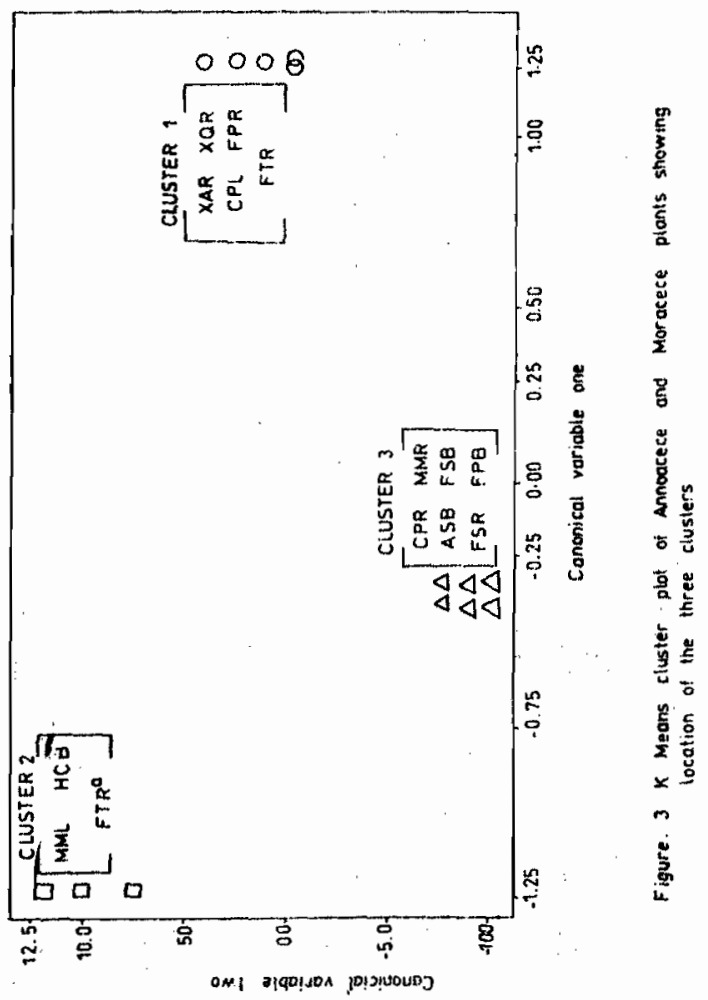

"K-means" plot which further exhibits the existence of clusters. Members of the clusters here also agree with those produced by FASTCLUS. High $\mathrm{R}^{2}$ (squared multiple correlation) is desirable to differentiate between clusters. Thus the highest $\mathrm{R}^{2}$ shown for $\mathrm{Ca}$ (0.883), $\mathrm{K}(0.713)$ and $\mathrm{Fe}(0.140)$ formed the clustering indices. The values for $\mathrm{Cd}$ and $\mathrm{Cu}$ 
were high because their raw values (Table 1) were relatively low for all the plant sampies analysed.

There seems to be a disparity between CLUSTER/TREE AND FASTCLUS/ CANDISC procedures in the placement of the plants $X Q R$ and CPL. These respectively placed both plants in groups 3 and 1 . The seeming anomaly arises from the range of elemental values used as clustering indices. Whereas TREE used Ca range of $21.0-32.5 \%$, (K range of $2.8-10 \%$ ), FASTCLUS/ CANDISC used $13.8-25 \% \mathrm{Ca}$ and $8.1-18 \% \mathrm{~K}$ for clusters 3 and 1 respectively. These ranges invariably displaced the plants XQR and CPL from cluster 3 (TREE) to cluster 1 (FASTCLUS), as XQR extract had $\mathrm{Ca}$ and $\mathrm{K}$ values of $21.9 \%$ and $8.1 \%$ while CPL recorded $21.0 \%$ and $10.0 \%$ for both metals. Besides the agreement between the two SAS procedures were indeed remarkable. A summary of the grouping is provided in Table 3 .

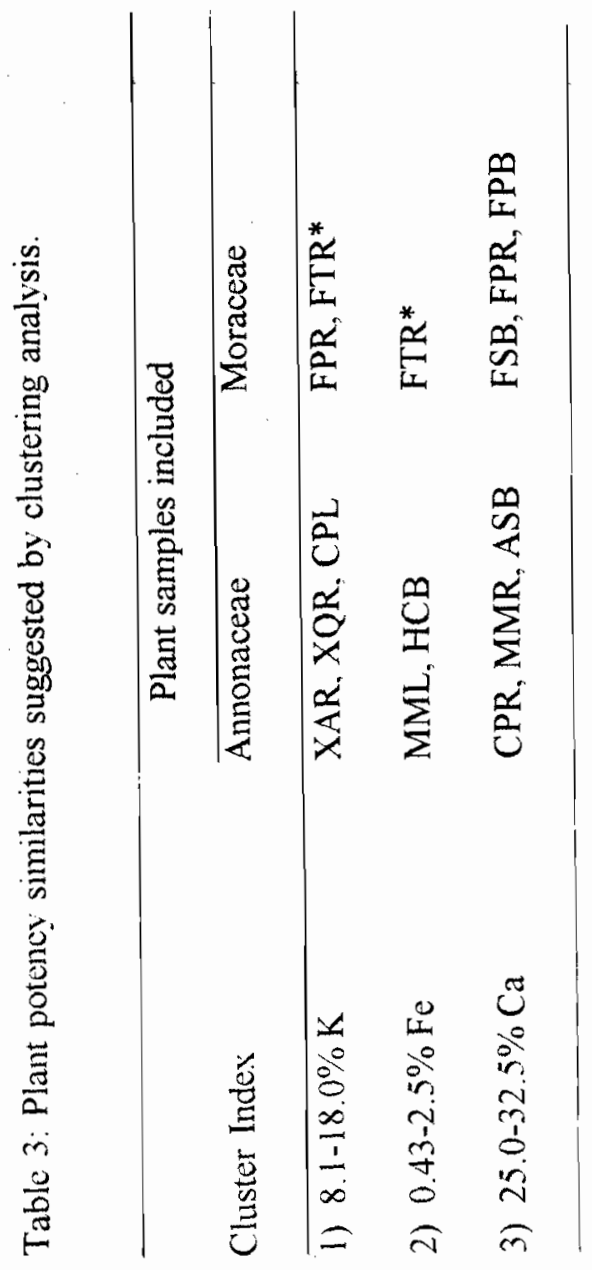

Medicinal efficacies of the plant extracts on animais:

Extract doses of FSE $(200 \mathrm{mg} / \mathrm{mil})$ and FPB (100 $\mathrm{mg} / \mathrm{ml})$, both increased the B.P. of the dogs and acted as depressant on the CNS of rabbits. Observed differing degrees of the effect between the plants in both tests may be discussed in terms of some of their metal conn. tents shown in Tables 1 and 4. Extracts of

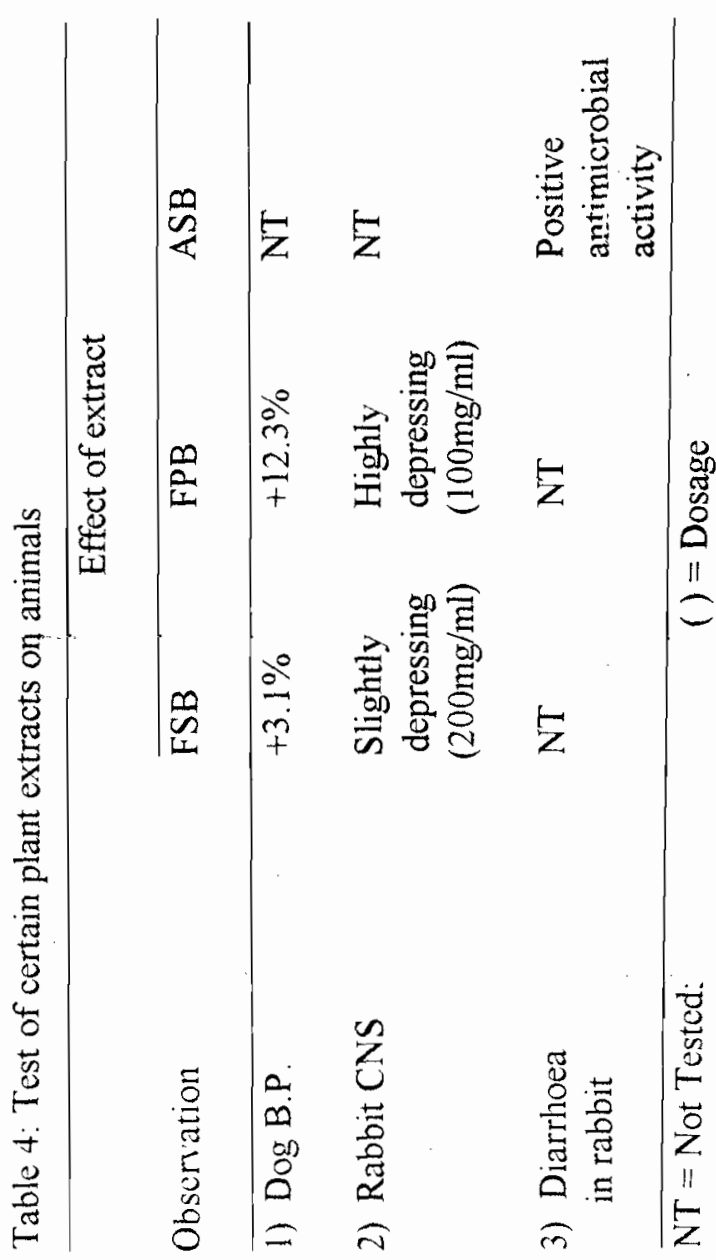

FSB with higher $\mathrm{Ca}$ and $\mathrm{Na}$ levels but lower $\mathrm{K}$. increased a dog's B.P. by $3.1 \%$ while FPB with lower $\mathrm{K}$ showed a four-fold increase over that of FSB. It appears that $K$ has an overriding effect on the B.P. as Ca. apparently. could not emol liate the effect of $K$ in FPB extract as it seems to have done on Na in FSB extract. For CNS. cetracts of FSB with a hundred and fifty orders of magnitude higher $\mathrm{Pb}$ content compared to FPB proved to be a lower depressant even with doublc the extract doses compared to FPB.

Potassium and sodium have been specifically mentioned for these as they have been medically associated with elcrated B.P. in man 
while $\mathrm{Pb}$ has been associated with mental disorder especially in children ${ }^{20}$. It was also reported $^{10}$ that extract doses of ASB showed positive antimicrobial activity when tested on rabbits. ASB had relatively high levels of $K$ and $\mathrm{Ca}$ but low levels of $\mathrm{Na}$ and $\mathrm{Pb}$ (Table 1).

A point to note here is that extracts of plants within a class reacted similarly towards respective ailments. If such classification is adopted it might save experimentation time as members of a group would then be subjected to similar tests. Moreover plants like FPB and ASB of different families but with similar elemental cuntents (Table 1) may show similar potency towards particular illnesses and ought to be tested as such.

\section{CONCLUSION}

SAS computer packages used respective concentration ranges of $\mathrm{K}, \mathrm{Fe}$ and $\mathrm{Ca}$ to efficiently place some of the Annonaceae and Moraceae families in three similarity clusters. The clustering exercise may have placed the plants in groups of equivalent potency towards particular illnesses treated by ATM.

\section{REFERENCES}

1. Hutchinson, J. and Dalziel, J.M., Flora of Tropical West Africa, 2nd ed. vol. 2., Crown Agents for Overseas Govt. and Admin., Millbark. London, 1963.

2. Akinniyi, J.A. and Sultanbawa, M.U.S., Annals of Borno, Vol. 1, 1983.

3. Burkill, H.M., The Useful Plants of Tropical West Africa, 2nd ed., Royal Botanical Gardens, London, 1985.

4. Vohora, S.B., Hist. Med., 1981, 1, 61.

5. Retnam. V.V.J. and Bhandarkar, J., J. Postgrad. Med.. 1981. 25 (3), 129.

6. Luckey, T.D. and Venugopal, B., Metal Toxicity in Mammals, 1, Physiology and Chemical Basis for Metal Toxicity, Plenum Press, New York, 1977.

7. Luckey, T.D. Venugopal, B and Hutchinson. J.. Heavy Metal Toxicity, Safety and Hormology, Vol. 1, George Thieme Verlag., New York, 1975.

8. O'Dell, B.L. and Campbell, B.J., In Florkin, M. and Slot, E.H. (eds.), Trace Elements in Comprehensive Biochemistry, Vol, 21, pp. 179 - 266, Elsevier Publishing Co., Amsterdam, 1971.
9. Underwood, E.J., Trace Elements in $\mathrm{Hu}$ man and Animal Nutrition, 3rd ed., Academic Press, New York, 1971.

10. Ogarawu, E.V., M.Sc. Thesis, University of Maiduguri, Nigeria, 1992.

11. Abdulrahman, F.I., M.SC, Thesis, University of Maiduguri, Nigeria, 1992.

12. SAS User's Guide: Statistics, SAS Institute Inc. Cary, N. Carolina, U.S.A., 1982.

13. Everitt, B.S., Cluster Analysis, 2nd ed.; Heinemann Educational Books Ltd., London, 1980.

14. Ogugbuaja, V.O., J. Environ Sci. Health, 1985, A20(5). 529

15. Kowalski B.R, Schatzki, T.F and Stross, F.H.. Anal. Chem.. 1972, 44, 2177.

16. Sneath, P.H.A and Sokal, R.R., Numerical Taxonomy, Freeman, San Francisco, 1973. 17. Hodson, F.R., World Archeol, 1969, 1, 90.

18. Charlton, T.H., Groce D.C and Hopke, P.K. Science, 1978. 201.807.

19. Anderberg; M.R., Cluster Analysis for Applications, Academic Press, New York, 1973.

20. Putnam, R.D., Am. Ind. Hyg. Assoc. J., $1986,47,700$.

accepted 29/6/98

received 30/9/97. 